\title{
Relations between ion signal and flame propagation in cylinder of a rapid compression machine
}

Internal combustion engine diagnostics using traditional methods of cylinder pressure signal processing limits the amount of information available about the combustion process. It is necessary to conduct research in order to obtain more precise information - increasing the combustion process diagnosis potential. One such suggestion is the use of an ionization signal and an attempt to link it to the flame development during combustion of gaseous fuels. The article attempts to identify such a relationship using a rapid compression machine due to optical access it provides to the combustion chamber. As a result of the research, the relationships between the ionization voltage (chemical and thermal) of the first combustion phase and the corresponding flame development rates were determined. A relatively high coefficient of determination value was obtained for both relations, which indicates the possibility of obtaining diagnostic information about the combustion process from the ionization signal.

Key words: ion current, flame speed, high speed camera, rapid compression machine

\section{Introduction}

Chemical reactions occurring during the combustion process in an internal combustion engine are complex and multi-stage. Simplifying the issue, it can be stated that hydrocarbons react with oxygen contained in the air, the product of which is carbon dioxide and water. In fact, other phenomena also occur, including ionization of molecules and atoms. The basic reactions of ion formation in a hydrocarbon flame are [5]:

$$
\begin{gathered}
\mathrm{CH}+\mathrm{O} \rightarrow \mathrm{CHO}^{+}+\mathrm{e}^{-} \\
\mathrm{CHO}^{+}+\mathrm{H}_{2} \mathrm{O} \rightarrow \mathrm{H}_{3} \mathrm{O}^{+}+\mathrm{CO} \\
\mathrm{CH}+\mathrm{C}_{2} \mathrm{H}_{2} \rightarrow \mathrm{C}_{3} \mathrm{H}_{3}^{+}+\mathrm{e}^{-}
\end{gathered}
$$

The ionization process that occurs in an internal combustion engine during the formation of a flame front in a combusted mixture is called chemical ionization $[1,5,9$, 10]. The presence of ions can be detected using an electric field. A flow of current proportional to the density of ions between the electrodes introduced into the volume of the cylinder, to which the potential difference is applied, can be measured. The current thus obtained is called the ionization current. In the spark-ignition engine, the role of the ionization current sensor can be played by the spark plug conventionally used to ignite the mixture $[4,8]$.

The recombination process is a reverse process to the process of ion formation, and it involves the combining of ions and free electrons. Under equilibrium conditions, the rates of ion formation and their recombination are equal [3].

A useful ionization current signal (Figs. 1 - D, E) as a function of time takes approximately the shape of interpenetrating Gaussian curves [5]. In the phase preceding the occurrence of the chemical ionization signal, there are a number of disturbances (A, B, C) coming from the ignition system. The part related to the flame front formed in the cylinder, the so-called chemical ionization (D) is characterized by a steep rise and a sudden decrease in value. The reason for the rapid changes is the rapid spread of flame in the measuring zone, as well as the presence of mainly free electrons with shorter lifetime [1]. The rate of ion formation in the rising part exceeds the rate of ion recombination, which results in an increase in signal value [5]. The signal amplitude represents the point at which the rate of recombination is equal to the rate of ion formation [3], while as the rate of recombination increases, the ionization current signal decreases in value.

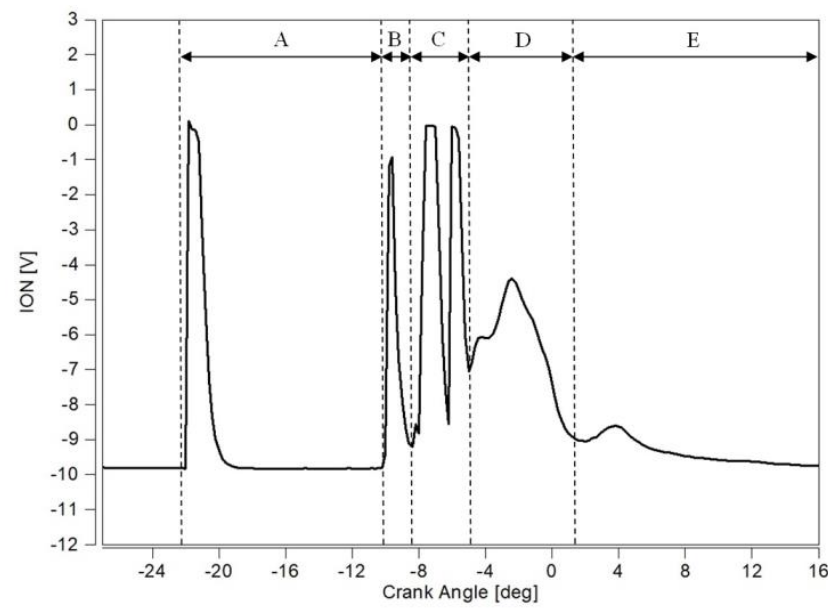

Fig. 1. Real ionization voltage signal with marked phases: A - ignition coil charging phase; $\mathrm{B}$ - discharge phase; $\mathrm{C}$ - phase of electromagnetic interference; $\mathrm{D}$ - chemical ionization phase; $\mathrm{E}$ - thermal ionization phase [6]

Assuming that the life time of ions is constant, one can expect a correlation between the nature of the ionization signal waveform and its amplitude and the flame propagation rate in which ions and free electrons are created in the chemical ionization process.

The goal of this work is to attempt to link the ionization current signal to the flame propagation speed in the RCM cylinder using a high-speed camera. Determining the relationship between the indicators will provide information on the possibility of linking the speed of flame development with an ionization signal. Consequently, it can allow to determine the local air excess ratio from the test cycle to the engine work cycle. 


\section{Method}

\subsection{Test object}

Due to the specific requirements for free optical access to the combustion chamber during the combustion process, the tests were performed using a rapid compression machine (RCM) - Fig. 2. The machine maps the single work cycle of a spark ignition engine to a speed corresponding to the engine speed of $500 \mathrm{rpm}$. RCM technical parameters are presented in Table 1.

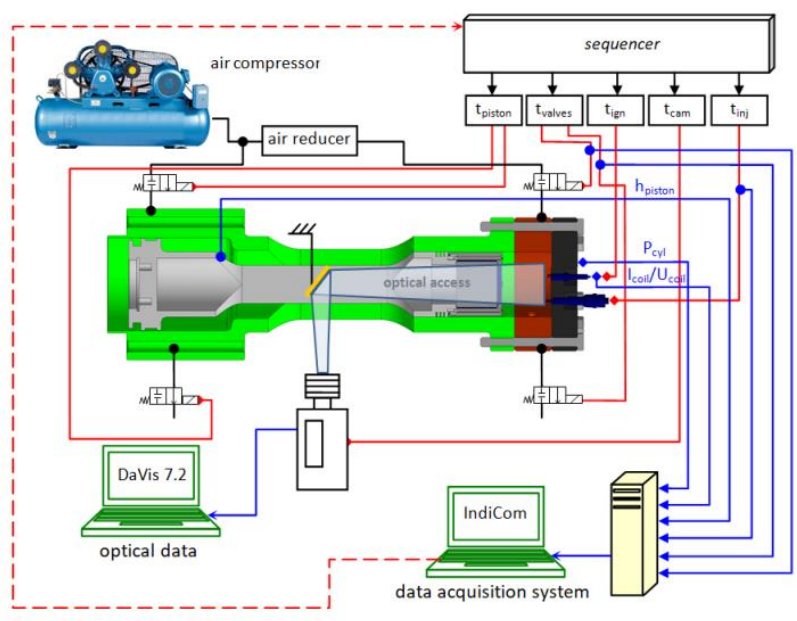

Fig. 2. Diagram of the test stand setup with instrumentation [11]

Table 1. Rapid compression machine parameters

\begin{tabular}{|l|c|}
\hline Parameter & Value \\
\hline Bore x stroke & $80 \times 90 \mathrm{~mm}$ \\
\hline Compression Ratio & 14,7 \\
\hline Speed & up to 500 rpm \\
\hline Ignition system & spark ignition \\
\hline Valves system & electromagnetic \\
\hline Fuel system & $\begin{array}{c}\text { direct gas-injection (NG) } \\
\text { (electromagnetic injector) }\end{array}$ \\
\hline Air system & naturally aspirated \\
\hline
\end{tabular}

The test object is a mechanical device with electromechanical elements regulating its operation. A series of pneumatic valves controls the piston movement and the supply and exhaust of gases from the combustion chamber. The test stand was equipped with a high-pressure air compressor supplying the pneumatic system (Fig. 3). In order to prepare the mixture in the cylinder, the RCM was equipped with direct gas injection. The spark plug was centrally located in the head. The sequencer with a trigger resolution of $1 \mathrm{~ns}$ was responsible for the order in which the subsequent devices were activated.

Data recording was done using the AVL IndiCom data acquisition system. During the tests, the pressure in the combustion chamber was recorded using the AVL GH14D piezoelectric sensor, as well as the ionization current signal using the Mazda Skyactive integrated ignition system. In addition, the following indicators were measured: voltage and discharge intensity at the spark plug, as well as piston paths in a rapid compression machine.
In order to determine the speed of flame development, a LaVision HSS5 high-speed camera was used. The camera uses a monochrome CMOS sensor and allows taking pictures with a frequency of up to $250,000 \mathrm{~Hz}$. The maximum available resolution was 1024 x 1024 pixels. The device is controlled using the DaVis 7.2 computer software.

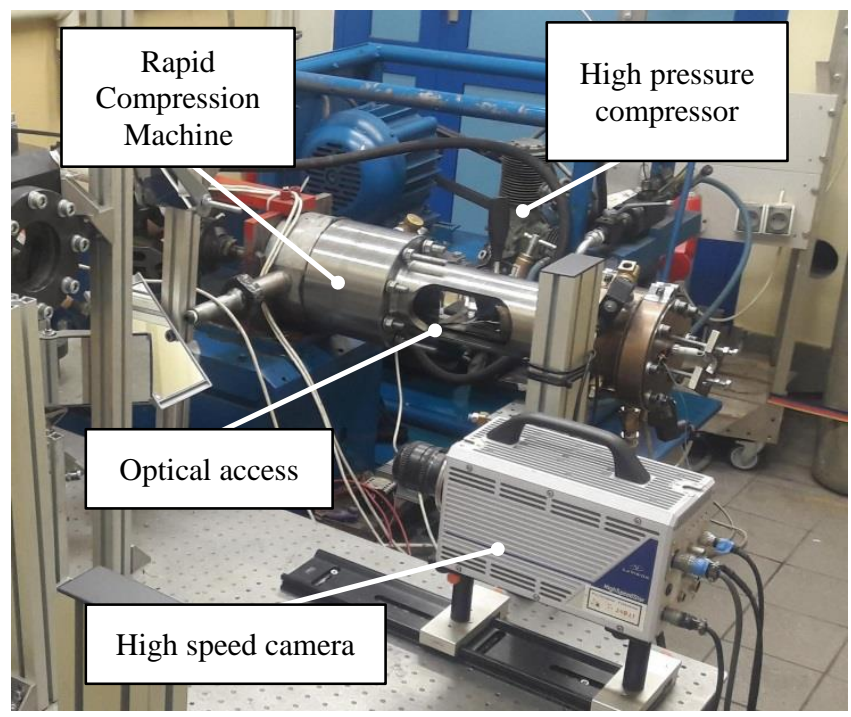

Fig. 3. Test stand for optical research on RCM

\subsection{Measurement plan}

Studies using a rapid compression machine were carried out in a sequence of 10 measuring cycles under repeatable thermodynamic conditions. The dose of methane delivered to the cylinder was determined based on the previously made injector characteristics: it was $32 \mathrm{mg}$ in each test. The linear speed corresponding to the engine speed $n=360 \mathrm{rpm}$ was thus obtained. The spark plug discharge was carried out on average $10 \mathrm{~ms}$ before TDC (Fig. 4).

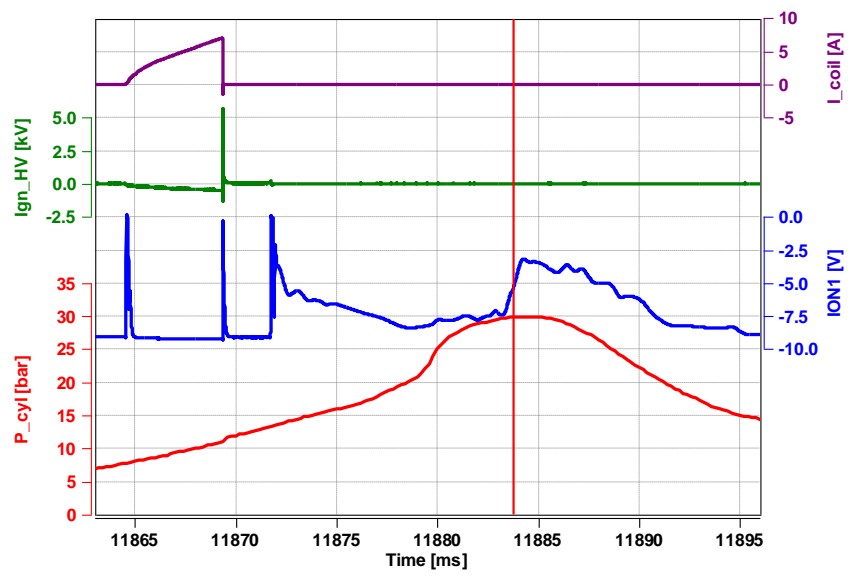

Fig. 4. An example of a pressure signal in a cylinder and electrical waveforms required for ionization signal analysis

The resistance of the spark plug used was $1.6 \mathrm{k} \Omega$, and the distance between the electrodes $\mathrm{d}=0.4 \mathrm{~mm}$. Other RCM operating conditions are presented in Table 2. 
Table 2. RCM operating conditions

\begin{tabular}{|l|c|}
\hline $\mathrm{n}_{\mathrm{av}}[\mathrm{rpm}]$ & 360 \\
\hline $\mathrm{q}_{0 \text { av }}[\mathrm{mg}]$ & 32 \\
\hline $\operatorname{Imax}_{\mathrm{av}}[\mathrm{A}]$ & 7 \\
\hline $\mathrm{Umax}_{\mathrm{av}}[\mathrm{kV}]$ & 4.6 \\
\hline $\mathrm{t}_{\mathrm{av}}[\mathrm{ms}$ before TDC] & 10.6 \\
\hline $\mathrm{R}[\mathrm{k} \Omega]$ & 1.6 \\
\hline $\mathrm{d}[\mathrm{mm}]$ & 0.4 \\
\hline \multirow{2}{*}{ camera } & $\mathrm{f}=5 \mathrm{kHz}$ \\
& $1024 \times 624 \mathrm{px}$ \\
\hline
\end{tabular}

The ionization signal was recorded using the AVL data acquisition system with a frequency of $200 \mathrm{kHz}$ (Fig. 5), while the frequency of taking pictures was $5 \mathrm{kHz}$. The camera optics were focused on the spark plug electrodes in the cylinder axis (Fig. 2), thus obtaining a flat image exposure. The resolution of the pictures taken was 1024 x 624 pixels.

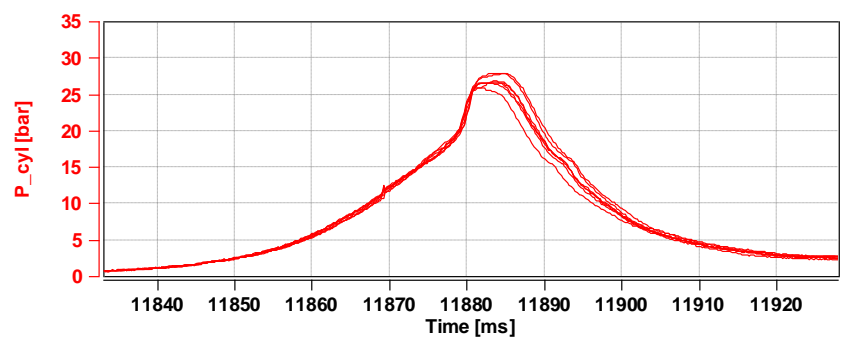

Fig. 5. Cylinder pressure curves indicating the non-repeatability of the work cycles

The analysis of the test results showed a partial nonrepeatability of subsequent RCM work cycles [2], therefore the data selection criterion presented in the previous work of the authors [7] was used.

Digital processing of the recorded photos was required to obtain the value of flame development speed. The LaVision camera manufacturer's software - DaVis 7.2 and an original program written in the internal language were used for this purpose. The image analysis algorithm is presented in detail in [7], and the schematic algorithm in Fig. 6.

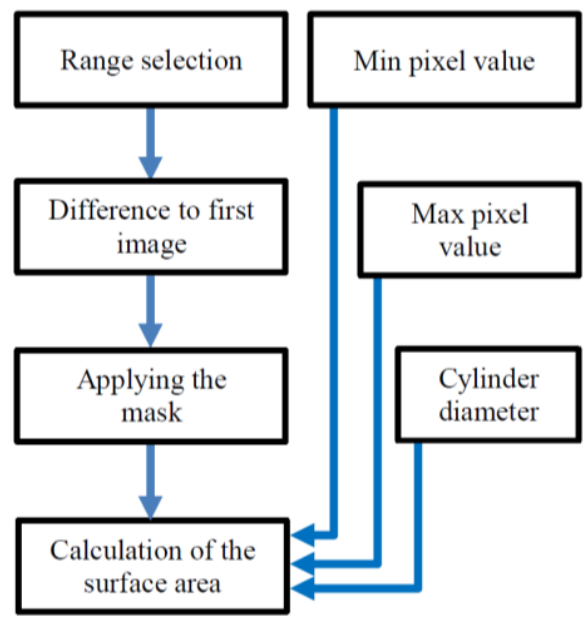

Fig. 6. Algorithm for analyzing images using the DaVis 7.2 program [7]

\section{Results}

The algorithm presented in chapter 2 was used to determine the surface occupied by the flame (expressed in $\mathrm{mm}^{2}$ ) in the combustion chamber of a rapid compression machine (Fig. 7). The flame propagation value expressed in $\mathrm{mm}^{2} / \mathrm{ms}$ was calculated for each cycle based on that data. The characteristics prepared in this way were compared with the ionization signal data (Fig. 8).

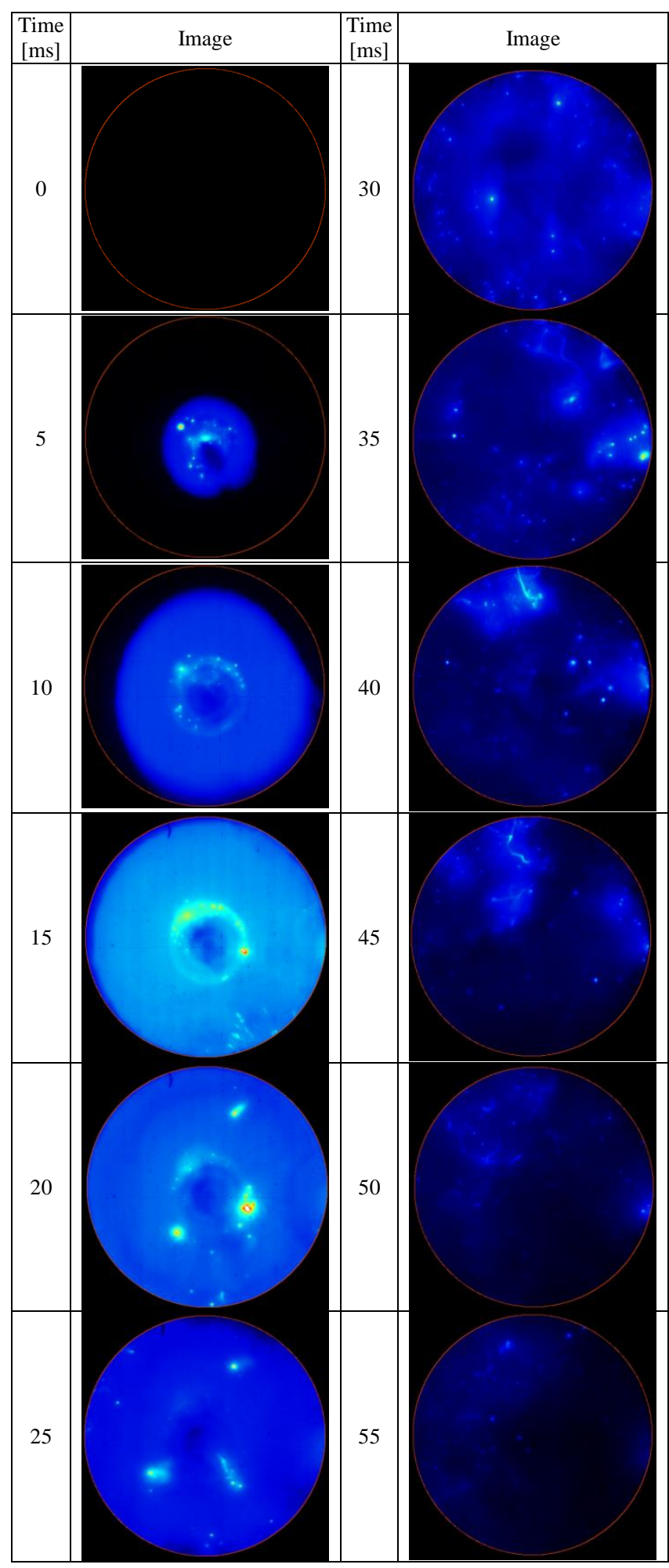

Fig. 7. Sample images of flame development in the combustion chamber 
a)

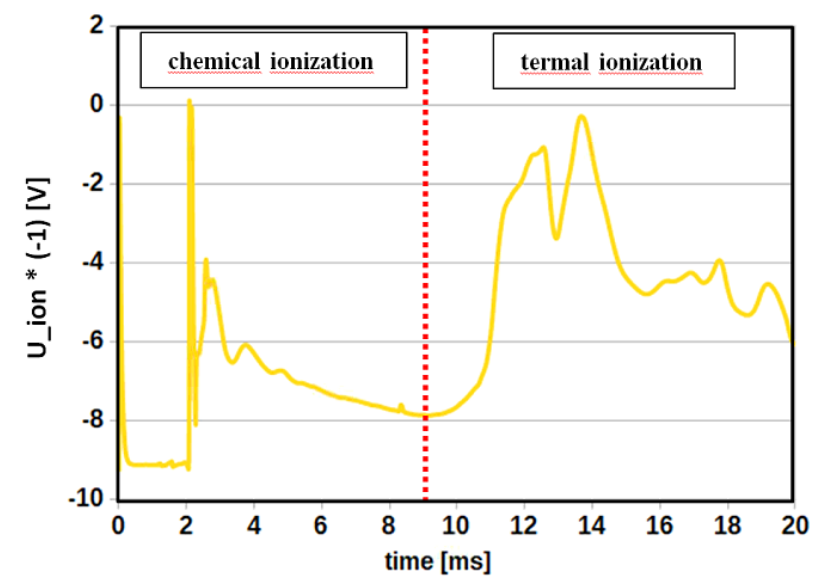

b)

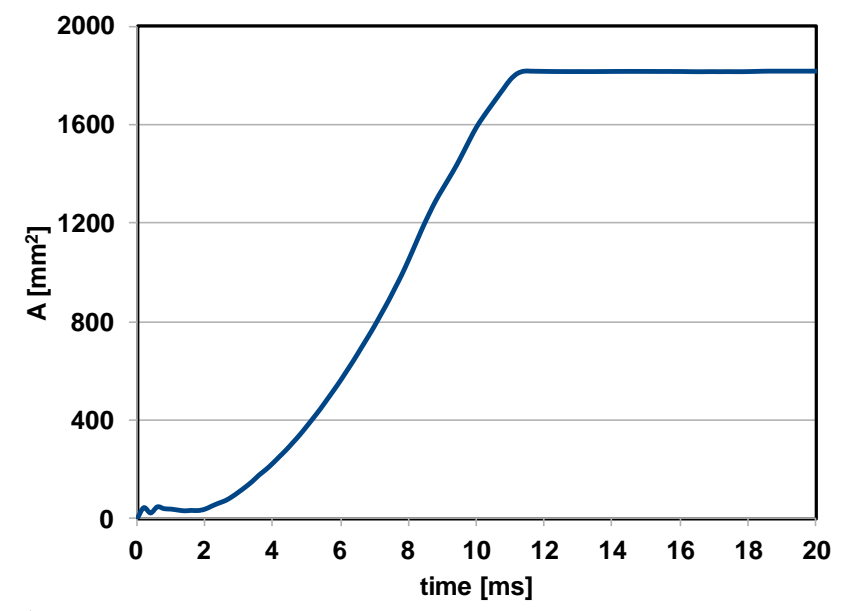

c)

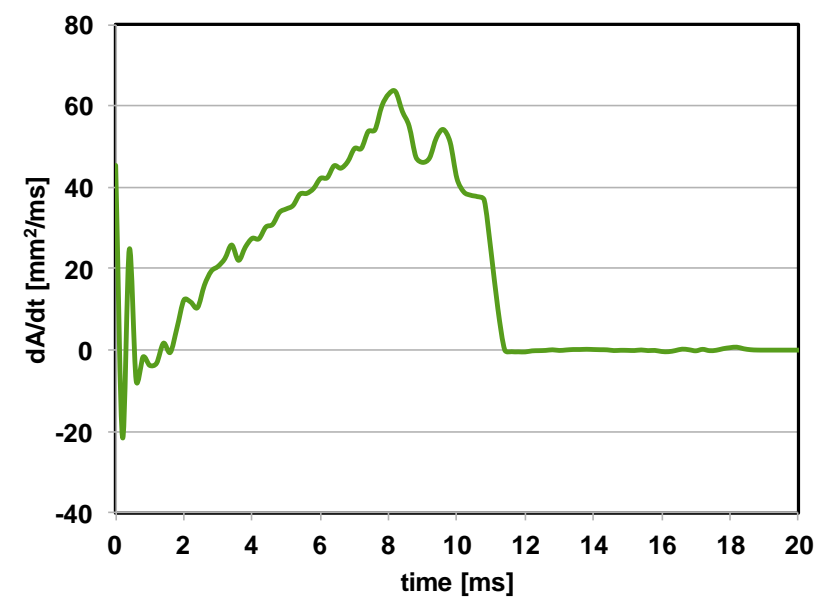

Fig. 8. The ionization voltage function in time (a) and the corresponding waveforms of the flame surface (b) and the speed of flame propagation (c) for a single RCM operating point

One of the criteria for comparing the flame propagation speed and the ionization signal was the coefficient of determination value for the correlation of the maximum chemical ionization signal value and the corresponding flame velocity value. An increase in flame front speed is synonymous with an increase in the rate of ion formation. Assuming a constant recombination time, one can expect an increase in their instantaneous quantity, and thus an increase in the value of the obtained ionization current signal. To confirm this theory, the maximum ionization voltage (proportional to ionization current) was measured in the chemical phase, which is closely related to the presence of flame between the spark plug electrodes. The flame propagation velocity in the time corresponding to the first ionization voltage measurement was also recorded. Thus, a correlation was obtained with the coefficient of determination reaching a value of $\mathrm{R}^{2}=0.65$ (Fig. 9). In addition, it was found that it was possible to achieve better correlation by increasing the number of operating cycles and eliminating reflections in the combustion chamber that interfered with accurate measurement.

Studies, carried out along the main research, on the correlation maximum ionization voltage value in the thermal phase and the maximum flame front propagation speed in the cylinder. It was assumed that the increase in flame speed leads to an increase in the engine thermal efficiency, which means that it is possible to achieve a higher maximum temperature and pressure in the cylinder. These indicators, in turn, affect the formation of ions in the so-called thermal phase. After determining the discussed values, the value of the coefficient of determination for the linear function was reached at the level of $\mathrm{R}^{2}=0.68$ (Fig. 10). As in the previous characteristics, it is possible to increase the correlation by eliminating reflections and increasing the number of attempts.

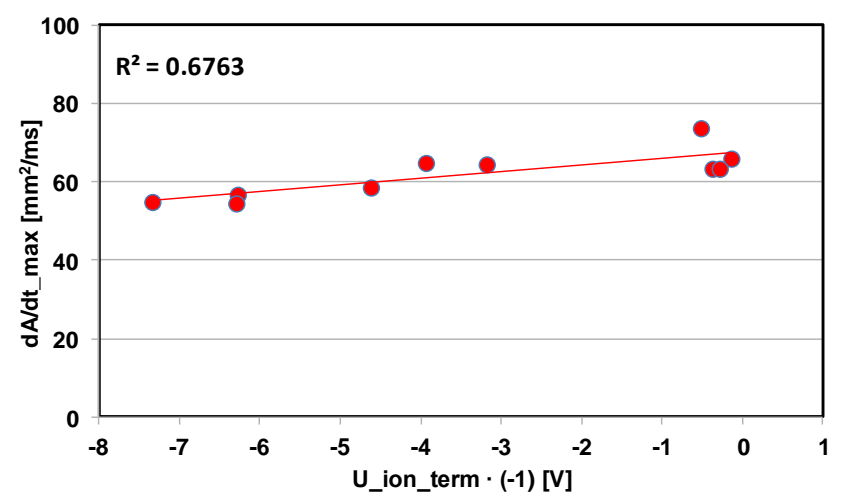

Fig. 9. Correlation between the value of flame propagation speed in the cylinder and the maximum value of chemical ionization voltage

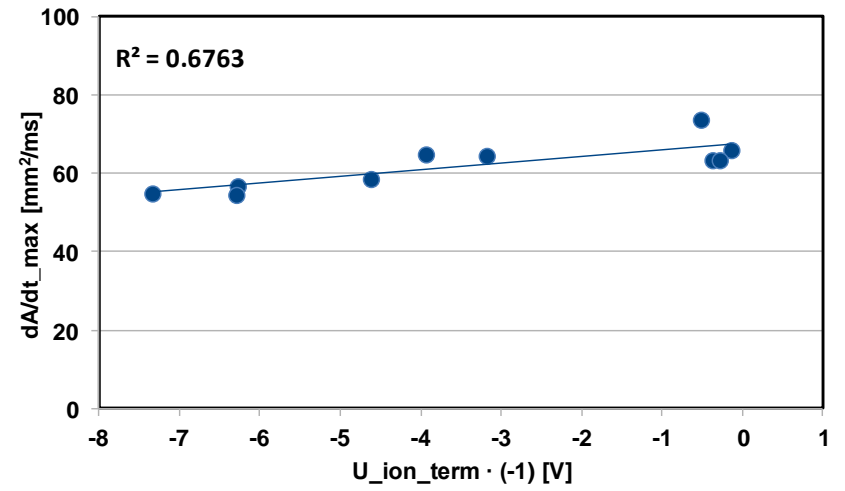

Fig. 10. Correlation of the maximum flame propagation value in the cylinder and the maximum value of thermal ionization voltage 


\section{Conclusions}

Based on the conducted research and analyzes, the following conclusions were presented.

1. A diagnostic assessment of the combustion process using an ionization signal is possible; flame development can be determined indirectly using another diagnostic signal.

2. The relationship between the flame ionization voltage signal in the chemical phase and the flame development rate was obtained with the determination coefficient value of $\mathrm{R}^{2}=0.65$, which indicates the possibility of indirect assessment of this quantity; despite many interfering signals, the obtained signal is characterized by high repeatability.
3. The correlation between the thermal ionization voltage signal and the development of the flame of this phase shows a greater correlation determined by the coefficient of determination of $\mathrm{R}^{2}=0.68$.

Adjusted ionization voltage signal indicators inside the combustion chamber can be successfully used as diagnostic indicators for an internal combustion engine. They are possible to obtain by much less complicated methods than attempts to determine the flame development in a traditional internal combustion engine. Therefore, systems using the signal of ionization voltage or current are systems that can significantly increase the scope of diagnostics of an internal combustion engine without the need for additional sensors or invasive systems in the combustion chamber of a spark ignition engine when combusting gas mixtures.

\section{Nomenclature}

$\mathrm{dA} / \mathrm{dt}$ rate of change of flame surface area

U_ion ionization voltage

$\mathrm{R} \quad$ coefficient of determination

A flame surface area

RCM rapid compression machine
CMOS complementary metal-oxide-semiconductor

Indexes

chem chemical

term thermal

\section{Bibliography}

[1] ANDERSSON, I. Cylinder pressure and ionization current modeling for spark ignited engines. Diploma Thesis 2002, Linkoping.

[2] BOROWSKI, P., CIESLIK, W., PIELECHA, I., WISŁOCKI, K. Evaluation of the repeatability of combustion process in rapid compression machine using optical research. XXII International Symposium on Combustion Processes. 22-25.9.2015, Poland.

[3] DANIELS, C.F. Mass fraction burned and pressure estimation through spark plug ion sensing. Patent US6089077A (2000).

[4] DEV, S., SANDHU, N.S., IVES, M. et al. Ion current measurement of diluted combustion using a multielectrode spark plug. SAE Technical Paper. 2018-011134. DOI:10.4271/2018-01-1134

[5] ERIKSSON, L. Methods for ionization current interpretation to be used in ignition control. Diploma Thesis 1995, Linkoping.

[6] FIEDKIEWICZ, Ł., PIELECHA, I. Assessment of possible use of the ionization signal for the combustion process diagnostics in a spark ignition combustion engine powered by natural gas. Eksploatacja

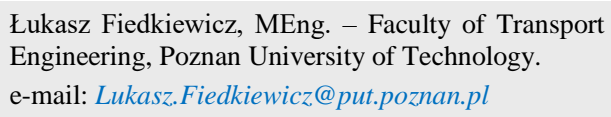

Prof. Ireneusz Pielecha, DSc., DEng. - Faculty of Transport Engineering, Poznan University of Technology.

e-mail: Ireneusz.Pielecha@put.poznan.pl 